\title{
Estado nutricional de pinheira sob adubação orgânica do solo ${ }^{1}$
}

\author{
Nutritional status of the sugar apple under organic fertilizing of the soil
}

\author{
Lourival Ferreira Cavalcante ${ }^{2}$, Walter Esfrain Pereira ${ }^{3}$, Carmen Rosa Silva Curvêlo ${ }^{4}$, José Adeilson Medeiros \\ Nascimento $^{5 *}$ e Ítalo Herbert Lucena Cavalcante ${ }^{6}$
}

\begin{abstract}
RESUMO - No período de agosto de 2009 a julho de 2010 foi desenvolvido um experimento em um pomar de pinheira (Annona squamosa L.), no município de Remígio, PB com o objetivo de avaliar os teores de macro e micronutrientes no tecido foliar das plantas em solo com esterco bovino e cama de frango. Os tratamentos foram distribuídos em blocos casualizados, com parcelas subdivididas no tempo, com três repetições e duas plantas por parcela, em esquema fatorial 2 $\times 5 \times 2$, referente a duas fontes de matéria orgânica de origem animal (esterco de bovino e cama de frango), cinco doses de matéria orgânica em volume $(0,0 ; 3,5 ; 5,3 ; 7,1$ e 8,9\%) e duas épocas de avaliação das plantas aos 36 e 48 meses após o transplantio. As doses de matéria orgânica foram definidas com base no teor de matéria orgânica de cada fonte. Com exceção de magnésio e zinco, as fontes de matéria orgânica não diferiram estatisticamente sobre os teores dos demais nutrientes na matéria seca foliar das plantas. A maior acumulação de nutrientes na matéria seca das folhas da pinheira ocorreu na amplitude das doses entre 6,01 e 8,65\% de matéria orgânica.
\end{abstract}

Palavras-chave: Fruta do conde. Esterco bovino. Cama de frango.

\begin{abstract}
From August 2009 to July 2010, an experiment was conducted in a sugar-apple orchard (Annona squamosa L.) in the town of Remigius PB, in order to evaluate the levels of macro and micronutrients and the leaf tissue of the plants in a soil treated with cattle manure and poultry litter. The treatments were distributed into randomized blocks, with plots split with time, three replications and two plants per plot, in a $2 \times 5 \times 2$ factorial arrangement, corresponding to two sources of organic matter of animal origin (cattle manure and poultry litter), five doses of organic material by volume $(0.0,3.5,5.3,7.1$ and $8.9 \%)$, and two periods of plant evaluation, 36 and 48 months after transplanting. The doses of organic material were set based on the organic-matter content of each source. With the exception of magnesium and zinc, the organic-matter sources did not differ statistically from the levels of other nutrients in the leaf dry-matter of the plants. The greatest accumulation of nutrients in the leaf dry-matter of the sugar apple was in the dosage-range of between 6.01 and $8.65 \%$ of organic matter.
\end{abstract}

Key words: Sugar apple. Cattle manure. Poultry litter.

\footnotetext{
* Autor para correspondência

${ }^{1}$ Recebido para publicação em 04/02/2011; aprovado em 28/02/2012

Pesquisa financiada pelo $\mathrm{CNPq}$

${ }^{2}$ Departamento de Solos e Engenharia Rural/CCA/UFPB, Vila Acadêmica, Areia-PB, Brasil, 58.397-000, lofeca@cca.ufpb.br

${ }^{3}$ Departamento de Ciências Fundamentais e Sociais/CCA/UFPB, Areia-PB, Brasil, 58.397-000, walter.ufpb@yahoo.com.br

${ }^{4}$ Programa de Pós-Graduação em Fitotecnia pela Universidade Federal de Viçosa, Viçosa-MG, Brasil, 36.571-000, carmencurvelo@yahoo.com.br

${ }^{5}$ Departamento de Fitotecnia pela Universidade Federal da Paraíba, Areia-PB, Brasil, 58.397-000, adeilsonagro@bol.com.br

${ }^{6}$ Universidade Federal do Piauí, Campus Profa. Cinobelina Elvas, BR-135, km 3, Bom Jesus- PI, Brasil, 64.900-000, italohlc@ufpi.edu.br
} 


\section{INTRODUÇÃO}

A pinheira, (Annona squamosa L.) é uma frutífera pertencente à família anonaceae, sendo uma das representantes mais importantes devido ao valor comercial de seus frutos em função do sabor bastante apreciado pelos consumidores (ZUCARELI et al., 2007). Seu cultivo vem aumentando consideravelmente nas regiões Sudeste e Nordeste do país, principalmente nos perímetros irrigados, pela possibilidade de mais de uma safra por ano e em razão dos bons preços obtidos para a fruta nos principais mercados consumidores (NIETSCHE et al., 2009).

É uma planta bastante exigente em nutrientes, principalmente, nitrogênio e potássio, quando comparada a outras culturas comerciais como abacaxi, abacate, laranja, banana e graviola. Entretanto, informações sobre os teores adequados de nutrientes na matéria seca dessa cultura são escassos na literatura pertinente, principalmente com relação aos micronutrientes. Segundo Silva e Silva (1997) a quantidade de nutrientes absorvida por essa cultura é quase o dobro da absorvida pela gravioleira.

Apesar de a exploração pinheira, assim como de outras anonáceas de importância econômica não ser recente no Brasil, as informações a respeito das exigências nutricionais na literatura pertinente (MARSCHENER, 1997; MALAVOLTA; VITTI; OLIVEIRA, 1997; DECHEN; NACHTIGALL, 2006) e manejo da adubação, principalmente orgânica, ainda são muito escassas para essa cultura. Dos poucos trabalhos realizados com nutrição de pinheira por Sadhu e Ghosh (1976), Silva et al. (1984) e, mais recentemente, por Santos et al. (2001) na Paraíba e Nascimento (2002) em Jales-SP registram-se teores de macro e micronutrientes no tecido foliar da cultura, porém os autores não citam se estes teores encontrados estão adequados ou não para essa cultura.

A falta de informações a respeito de adubação orgânica de pinheira e sua nutrição, juntamente com elevação do preço dos fertilizantes minerais nos últimos anos, são fatores que contribuem expressivamente para aumento na procura e estudo de fontes alternativas de nutrientes para as culturas (VIDIGAL et al., 2010). Além disso, os custos ambientais, exploração de áreas pequenas com essa cultura e as satisfatórias respostas à adubação orgânica apresentadas por plantas do mesmo gênero, como a graviola (SÃO JOSÉ, 2003), são fatores que estimulam pesquisas com adubação orgânica na pinheira visando à substituição parcial ou até total de insumos sintéticos.

A utilização de estercos é uma alternativa amplamente adotada para o suprimento de nutrientes, principalmente nitrogênio e fósforo, em áreas de agricultura familiar na região semi-árida e agreste do Nordeste do Brasil (MENEZES; SALCEDO, 2007). O uso de fertilizantes inorgânicos nessas regiões é pouco freqüente devido ao limitado poder aquisitivo dos produtores de baixa renda, à dificuldade de acesso ao crédito agrícola e à elevada variabilidade na precipitação pluvial.

O esterco bovino pode fornecer teores adequados de macro e micronutrientes para o crescimento das culturas e incrementa a quantidade de matéria orgânica do solo, sendo uma alternativa de baixo custo para os fertilizantes minerais (LAZCANO; GÓMEZ-BRAWDOW, 2008). Além disso, esse é muito encontrado em pequenas e grandes propriedades rurais do Nordeste brasileiro devido a maior parte dos produtores explorarem a criação de bovinos.

A cama de frango é um dos insumos orgânicos mais ricos em nutrientes, quando comparado aos estercos de bovinos, caprinos e suínos, que são comumente utilizados na agricultura, sendo bastante utilizado como fonte de nutrientes para as plantas (AZZEZ; AVERBEKE; OKOROGBONA, 2010). Esse insumo geralmente apresenta altos níveis de fósforo, potássio, cálcio e magnésio, o que o torna um fertilizante orgânico com potencial de uso em várias culturas (FARIDULLAH et al., 2008). Objetivou-se com este trabalho, avaliar os teores de macro e micronutrientes em pinheira adubada com esterco bovino e cama de frango.

\section{MATERIAL E MÉTODOS}

O trabalho foi desenvolvido no período de agosto de 2009 a julho de 2010 em um pomar de pinheira (Annona squamosa L.), cujas plantas foram obtidas por via seminífera no município de Remígio - PB. O solo da área experimental é classificado como Cambissolo Húmico distrófico (SANTOS et al., 2006), na faixa de 0-40 cm é de textura franco arenosa e antes da instalação do experimento apresentava as seguintes características químicas: $\mathrm{pH}\left(\mathrm{H}_{2} \mathrm{O}\right)=5,8 ; \mathrm{P}=6 \mathrm{mg} \mathrm{kg}^{-1} ; \mathrm{K}^{+}=0,3 \mathrm{cmol}_{\mathrm{c}}$ $\mathrm{dm}^{-3} ; \mathrm{Ca}^{2+}=1,0 \mathrm{cmol}_{c} \mathrm{dm}^{-3} ; \mathrm{Mg}^{2+}=0,6 \mathrm{cmol}_{c} \mathrm{dm}^{-3} ; \mathrm{Na}^{+}=$ $0,05 \mathrm{cmol}_{\mathrm{c}} \mathrm{dm}^{-3} ; \mathrm{H}^{+}=1,16 \mathrm{cmol}_{\mathrm{c}} \mathrm{dm}^{-3} ; \mathrm{MO} \stackrel{\mathrm{c}}{=} 5 \mathrm{~g} \mathrm{dm}^{-3} . \mathrm{O}$ clima da região é quente úmido, com chuvas mais frequentes de março ou abril até julho ou agosto.

Os tratamentos foram distribuídos em blocos casualizados em parcelas subdivididas no tempo, com três repetições e duas plantas por parcela, em esquema fatorial $2 \times 5 \times 2$, referente às fontes de matéria orgânica oriundas de esterco de bovino e cama de frango 
aplicadas em cinco doses, aos níveis percentuais de $0 ; 3,5 ; 5,3 ; 7,1$ e $8,9 \%$ do volume de uma cova de $60 \mathrm{~L}$ e duas épocas de avaliação, aos 36 e 48 meses após o plantio. A aplicação de cada dose de esterco foi realizada em uma faixa de $60 \mathrm{~cm}$ de espessura e $2 \mathrm{~cm}$ de profundidade, sob a projeção da copa. Esta faixa foi aberta a uma distância de $50 \mathrm{~cm}$ do caule, por ser a área que concentra um maior número de raízes superficiais. As fontes de matéria orgânica e respectivos teores macronutrientes estão apresentados na Tabela 1 .

Para se fornecer o mesmo valor de matéria orgânica de cada insumo tomou-se o esterco bovino como padrão, dividiu-se o seu valor de matéria orgânica (560 $\mathrm{g} \mathrm{dm}^{-3}$ ), pelo da cama de frango $\left(450 \mathrm{~g} \mathrm{dm}^{-3}\right)$ e obteve-se o coeficiente de 1,24. Esse coeficiente foi multiplicado por cada valor referente aos volumes do esterco bovino para obtenção dos volumes de cama de frango. Os volumes de esterco bovino foram $0 ; 2,10$; 3,$06 ; 4,26$ e $5,34 \mathrm{~L}$ e da cama de frango $0 ; 2,61 ; 3,80$; 5,28 e $6,62 \mathrm{~L}$. Ambos os insumos foram colocados em estufa à temperatura de $65^{\circ} \mathrm{C}$ para reduzir os respectivos valores de umidade ao nível de $5 \%$.

A aplicação da matéria orgânica foi feita na projeção da área da copa das plantas no início do período de estiagem (agosto de 2009) e a cada 120 dias. Com a finalidade de reduzir os efeitos das perdas hídricas por evaporação, as covas foram protegidas no raio de projeção da copa com camadas de $5 \mathrm{~cm}$ de capim braquiária desidratado. Até o mês de setembro de 2009 as plantas foram irrigadas diariamente com 30 litros de água aplicados pelo método de irrigação localizada por gotejamento, utilizando 4 emissores tipo "Katif" com vazão de $3,75 \mathrm{~L} \mathrm{~h}^{-1}$.

No início do período chuvoso de 2009 e 2010, foram aplicados por planta, $100 \mathrm{~g}$ de uréia (44\% de $\mathrm{N})$, $300 \mathrm{~g}$ de fosfato natural ( $24 \%$ de $\mathrm{P}_{2} \mathrm{O}_{5}$ total e $26 \%$ de $\mathrm{CaO}$ ) e $100 \mathrm{~g}$ de cloreto de potássio. No início da estiagem, aos 36 e 48 meses de idade das plantas, foram coletadas 40 folhas por parcela experimental, na parte mediana da copa, para a avaliação do estado nutricional das plantas em macro e micronutrientes, adotando metodologia sugerida por Malavolta, Vitti e Oliveira (1997).

Os dados foram submetidos à análise de variância pelo teste "F" e regressão polinomial para doses de matéria orgânica. Para o processamento dos dados foi utilizado o programa estatístico SAS.

\section{RESULTADOS E DISCUSSÃO}

A interação idade das plantas $\mathrm{x}$ fonte $\mathrm{x}$ dose de matéria orgânica, com exceção do teor de magnésio, não exerceu influência significativa sobre os teores dos macros e micronutrientes avaliados na matéria seca foliar da pinheira (Tabela 2), sendo verificado efeito isolado da idade e das doses sobre os teores de nitrogênio, fósforo, potássio e boro e interação idade $\mathrm{x}$ dose sobre os teores de cálcio, magnésio, enxofre, cobre e ferro.

Independentemente da fonte de matéria orgânica aplicada, o incremento das doses elevaram os teores de nitrogênio, fósforo e potássio da matéria seca foliar da pinheira (Figura 1A, 2A e 3A), obtendo-se os valores máximos $30 \mathrm{~g} \mathrm{~kg}^{-1}$ de $\mathrm{N}, 1,79 \mathrm{~g} \mathrm{~kg}^{-1}$ de $\mathrm{P}$ e $18,06 \mathrm{~g} \mathrm{~kg}^{-1}$ de $\mathrm{K}$, correspondentes às doses 6,26; 6,92 e 6,60\% de matéria orgânica, respectivamente. Com relação às épocas de avaliação do estado nutricional, verifica-se que as plantas apresentaram maiores teores de $\mathrm{N}, \mathrm{Pe} \mathrm{K}$ aos 36 meses de idade (Figura 1B, 2B e 3B), talvez em função das plantas aos 48 meses estarem em produção e deslocarem nutrientes para a formação de flores e produção dos frutos, o que também foi observado por Silva et al. (1984) ao constatarem menores teores de $\mathrm{N}$ e $\mathrm{P}$ em plantas de pinheira em fase produtiva em relação às plantas sem frutificação. Estes valores superam os valores de N, P e K obtidos por Nascimento et al. (2002) em pomares de pinheira na região de Jales em São Paulo.

Tabela 1 - Composição química de cada fonte de matéria orgânica utilizada na adubação das plantas

\begin{tabular}{|c|c|c|c|c|c|c|c|}
\hline \multirow{2}{*}{ Fonte de $\mathrm{MO}$} & $\mathrm{N}$ & $\mathrm{P}$ & $\mathrm{K}$ & $\mathrm{Ca}$ & $\mathrm{Mg}$ & MO & $\mathrm{U}$ \\
\hline & ----------- & ---- & $-\mathrm{g} \mathrm{kg}^{-1}$ & ------ & --------- & $\mathrm{g} \mathrm{kg}^{-1}$ & $\mathrm{~g} \mathrm{~kg}^{-1}$ \\
\hline $\mathrm{EB}$ & 13,65 & 4,04 & 26,22 & 10,26 & 13,08 & 560 & 1164 \\
\hline $\mathrm{CF}$ & 18,2 & 11,18 & 18,31 & 21,17 & 9,49 & 450 & 459 \\
\hline
\end{tabular}

$\mathrm{EB}=$ esterco bovino; $\mathrm{CF}=$ cama de frango; $\mathrm{MO}=$ matéria orgânica; $\mathrm{U}=$ umidade 
Tabela 2 - Resumo da análise de variância, pelo quadrado médio, referente aos teores foliares de nitrogênio (N), fósforo (P), potássio $(\mathrm{K})$, cálcio $(\mathrm{Ca})$, magnésio $(\mathrm{Mg})$, enxofre $(\mathrm{S})$, boro $(\mathrm{B})$, cobre $(\mathrm{Cu})$, ferro $(\mathrm{Fe})$ e zinco $(\mathrm{Zn})$ em pinheira submetida fontes e doses de adubação orgânica

\section{QUADRADO MÉDIO}

\begin{tabular}{|c|c|c|c|c|c|c|c|c|c|c|c|}
\hline \multirow{2}{*}{ F.V. } & \multirow{2}{*}{ G.L } & & & & & & & & & & \\
\hline & & $\mathrm{N}$ & $\mathrm{P}$ & K & $\mathrm{Ca}$ & $\mathrm{Mg}$ & S & B & $\mathrm{Cu}$ & $\mathrm{Fe}$ & $\mathrm{Zn}$ \\
\hline Bloco & 2 & $1,32^{\mathrm{ns}}$ & $0,03^{\mathrm{ns}}$ & $1,92^{\mathrm{ns}}$ & $0,00^{\mathrm{ns}}$ & $0,14^{\mathrm{ns}}$ & $0,12^{\mathrm{ns}}$ & $0,80^{\mathrm{ns}}$ & $0,50^{\mathrm{ns}}$ & $39,78^{\mathrm{ns}}$ & $3,16^{\mathrm{ns}}$ \\
\hline Idade (I) & 1 & $469,84 * *$ & $1,53^{* *}$ & $140,45 * *$ & $931,41^{* *}$ & $6,73 * *$ & $355,75 * *$ & $375,00 * *$ & $62,63^{*}$ & $39,68 * *$ & $34,35^{*}$ \\
\hline Res. (a) & 2 & 1,24 & 0,01 & 1,35 & 0,14 & 0,02 & 0,09 & 0,8 & 1,86 & 5,85 & 1,48 \\
\hline Fontes $(\mathrm{F})$ & 1 & $11,88^{\mathrm{ns}}$ & $0,05^{\mathrm{ns}}$ & $0,00^{\mathrm{ns}}$ & $0,60^{\mathrm{ns}}$ & $2,52 * *$ & $1,63^{\mathrm{ns}}$ & $48,60^{\mathrm{ns}}$ & $0,40^{\mathrm{ns}}$ & $91,02^{\mathrm{ns}}$ & $84,01 * *$ \\
\hline Dose (D) & 4 & $424,17 * *$ & $3,41 * *$ & $213,06^{* *}$ & $193,46^{* *}$ & $6,22 * *$ & $60,33^{* *}$ & $1036,35 * *$ & $30,56^{* *}$ & $11904,32 * *$ & $232,72 * *$ \\
\hline$I \times F$ & 1 & $0,16^{\mathrm{ns}}$ & $0,02^{\mathrm{ns}}$ & $0,86^{\mathrm{ns}}$ & $2,90^{\mathrm{ns}}$ & $2,88 * *$ & $0,93^{\mathrm{ns}}$ & $21,60^{\text {ns }}$ & $0,08^{\mathrm{ns}}$ & $1276,05 * *$ & $119,85^{* *}$ \\
\hline$I \times D$ & 4 & $17,57^{\mathrm{ns}}$ & $0,01^{\mathrm{ns}}$ & $6,29^{\text {ns }}$ & 62,82 ** & $0,81 * *$ & $27,22 * *$ & $9,00^{\mathrm{ns}}$ & $7,68 * *$ & $3022,89^{* *}$ & $5,98^{\mathrm{ns}}$ \\
\hline I x F x D & 4 & $3,96^{\mathrm{ns}}$ & $0,00^{\mathrm{ns}}$ & $0,11^{\mathrm{ns}}$ & $0,18^{\mathrm{ns}}$ & $0,36^{*}$ & $0,06^{\mathrm{ns}}$ & $2,85^{\mathrm{ns}}$ & $0,26^{\mathrm{ns}}$ & $85,67^{\mathrm{ns}}$ & $7,32^{\mathrm{ns}}$ \\
\hline Res. (b) & 40 & 7,376 & 0,04 & 2,77 & 2,2 & 0,11 & 0,45 & 13,88 & 0,71 & 132,4 & 2,99 \\
\hline $\mathrm{CV}$ a $(\%)$ & & 4,31 & 5,25 & 7,63 & 3,44 & 6,2 & 5,24 & 2,59 & 20,62 & 2,12 & 8,34 \\
\hline $\mathrm{CV} b(\%)$ & & 10,49 & 14,29 & 10,92 & 13,42 & 13,49 & 11,31 & 10,77 & 12,7 & 10,11 & 11,85 \\
\hline
\end{tabular}

$\overline{\mathrm{GL}}=$ grau de liberdade; $\mathrm{ns}=$ não significativo; $* \mathrm{e} * *$ respectivamente significativos para $\mathrm{p}<0,05$ e $\mathrm{p}<0,01 ; \mathrm{CV}=$ Coeficiente de variação

Figura 1 - Teores de nitrogênio em matéria seca foliar de pinheira em função de doses de matéria orgânica (A) aos 36 e 48 meses após plantio (B), em Remígio, 2010
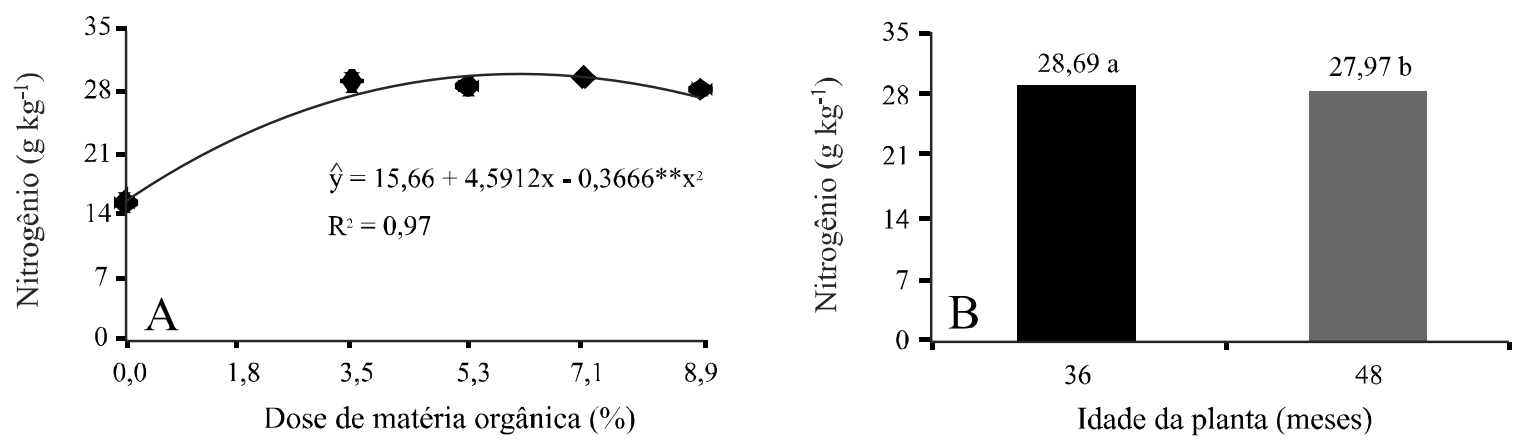
Figura 2 - Teores de fósforo em matéria seca foliar de pinheira em função de doses de matéria orgânica (A) aos 36 e 48 meses após plantio (B), em Remígio, 2010
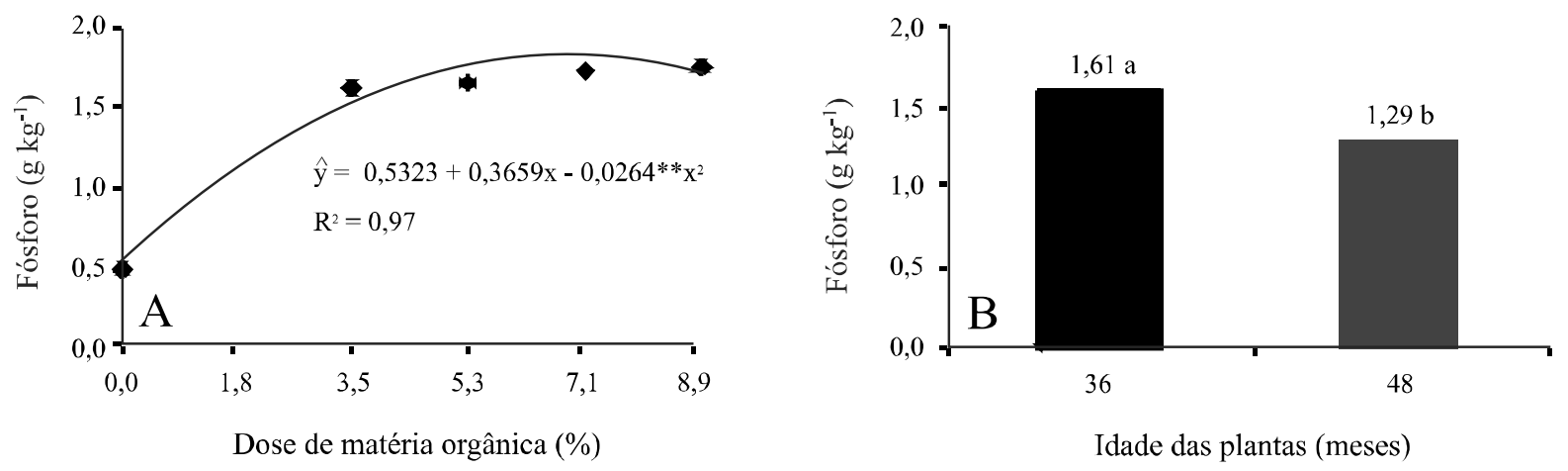

Figura 3 - Teores de potássio em matéria seca foliar de pinheira em função de doses de matéria orgânica (A) aos 36 e 48 meses após plantio (B), em Remígio, 2010

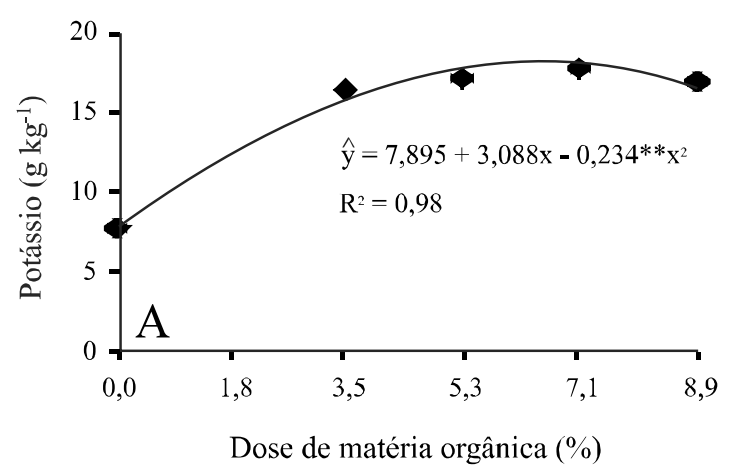

De acordo com Sadhu e Ghosh (1976) para serem considerados adequados, os teores de $\mathrm{N}$ na matéria seca foliar de pinheira devem estar entre 28,5 e $33,6 \mathrm{~g} \mathrm{~kg}^{-1}$, os de $\mathrm{P}$ acima de 3,4 $\mathrm{g} \mathrm{kg}^{-1}$ e os de $\mathrm{K}$ entre 8,7 e 24,7 $\mathrm{g} \mathrm{kg}^{-1}$, o que indica que pelos resultados obtidos, as plantas estavam adequadamente supridas em $\mathrm{N}$ e $\mathrm{K}$, mas deficientes em P. A deficiência em fósforo possivelmente foi provocada pelas baixas quantidades deste elemento disponibilizadas ao solo pelo fosfato natural, devido à baixa solubilidade desse insumo em relação às fontes sintéticas de fósforo (BHATTI; YAWAR, 2010). Outro fator que pode ter contribuído para essa deficiência seria a precipitação do $\mathrm{P}$ do solo com o cálcio, formando compostos de baixa solubilidade, devido a elevação do $\mathrm{pH}$ provocada pelo cálcio do fosfato natural e os altos teores de cálcio e magnésio contidos nos insumos orgânicos aplicados (Tabela 1), além disso o solo apresentava teor médio de fósforo, o que pode ter contribuído para adsorção de parte do P existente na matéria orgânica aplicada (SOUZA et al., 2010). Por outro lado, os teores adequados de $\mathrm{N}$ e K na

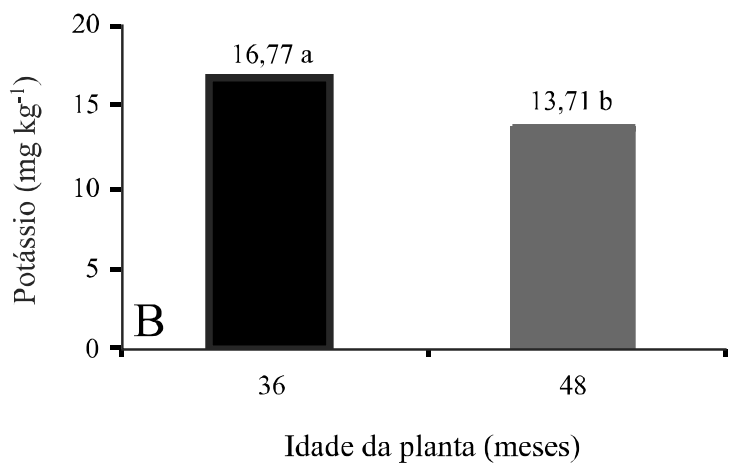

matéria seca foliar se devem aos teores desses elementos contidos nos estercos aplicados, o que é confirmado por Lazcano; Gómez-Brandón e Dominguez (2008) e Azzez, Averbeke e Okorogbona (2010), e no caso especifico do $\mathrm{K}$ se deve também ao teor pré-existente no solo, que é considerado como bom.

Aos 36 meses de idade, independentemente da fonte de matéria orgânica aplicada, os teores de cálcio foram elevados de forma linear, com um aumento de 0,48 $\mathrm{g} \mathrm{kg}^{-1}$ de cálcio por cada aumento unitário de matéria orgânica (Figura 4). Os resultados obtidos nas plantas com 48 meses se ajustaram ao modelo quadrático, com a dose $6,92 \%$ de MO correspondente ao teor máximo 19,08 $\mathrm{g} \mathrm{kg}^{-1}$ de cálcio. Comparativamente, este valor supera os $17,4 \mathrm{~g} \mathrm{~kg}^{-1}$ obtidos por Santos et al. (2001), mas é inferior aos $54,5 \mathrm{~g} \mathrm{~kg}^{-1}$ obtidos por Nascimento et al. (2002). Silva e Silva (1997) afirmam que a pinheira absorve quase o dobro das quantidades de nutrientes absorvidos pela gravioleira, assim sendo, 
como os valores adequados de cálcio no tecido foliar de gravioleira estão entre 8,2 e $16,8 \mathrm{~g} \mathrm{~kg}^{-1}$. Então se infere que o valor $19,08 \mathrm{~g} \mathrm{~kg}^{-1}$ obtido neste trabalho é considerado inadequado para a pinheira. Como o cálcio compete com o potássio pelos sítios de absorção na membrana plasmática, os altos teores de potássio do solo e nos insumos orgânicos podem ter influenciado negativamente a absorção de cálcio pelas plantas (MALAVOLTA; VITTI; OLIVEIRA, 1997). Além disso, os teores de cálcio das plantas foram superiores quando estas estavam com 48 meses de idade, o que possivelmente seja devido a nessa idade as plantas estarem começando a fase produtiva exigindo maiores teores deste nutriente.

Figura 4 - Teores de cálcio em matéria seca foliar de pinheira em função de doses de matéria orgânica aos 36 (-) e 48 (---) meses após plantio, em Remígio, 2010

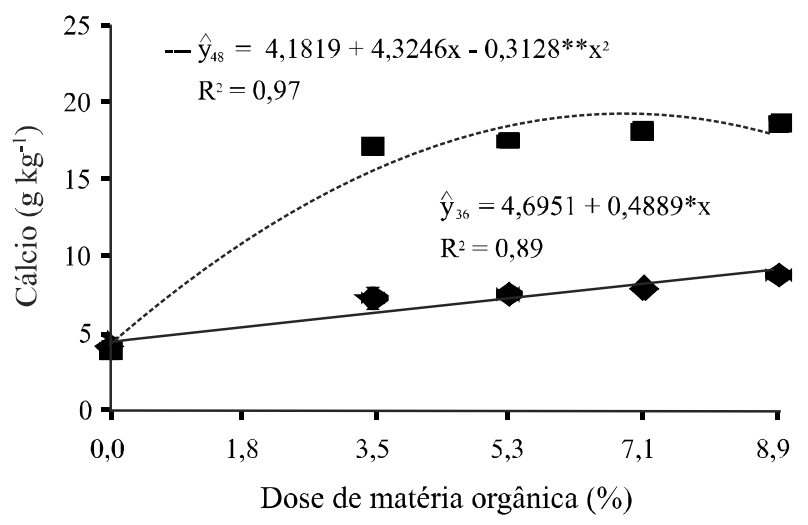

Aos 36 meses de idade, as plantas tratadas com esterco bovino, apresentaram um aumento linear de 1,54 para 2,68 $\mathrm{g} \mathrm{kg}^{-1}$ nos teores de magnésio do tecido foliar, mas aos 48 meses os teores ajustaram-se ao modelo quadrático com o valor máximo $2,94 \mathrm{~g} \mathrm{~kg}^{-1}$ correspondente à dose 7,76\% de MO (Figura 5A). Nos tratamentos com cama de frango, ocorreu o contrário do verificado com esterco bovino, onde as plantas com 36 meses tiveram os teores de magnésio ajustados ao modelo quadrático, com a dose $8,65 \%$ de matéria orgânica correspondente ao teor máximo de $2,54 \mathrm{~g} \mathrm{~kg}^{-1}$ de magnésio, enquanto que nas plantas com 48 meses as doses de MO proporcionaram aumento linear, com um acúmulo de $0,36 \mathrm{~g} \mathrm{~kg}^{-1}$ de magnésio por cada aumento unitário de MO (Figura 5B).
Figura 5 - Teores de magnésio em matéria seca foliar de pinheira em função de doses de matéria orgânica, proviniente de esterco bovino (A) e cama de frango (B) aos 36 (-) e 48 (---) meses após plantio, em Remígio, 2010
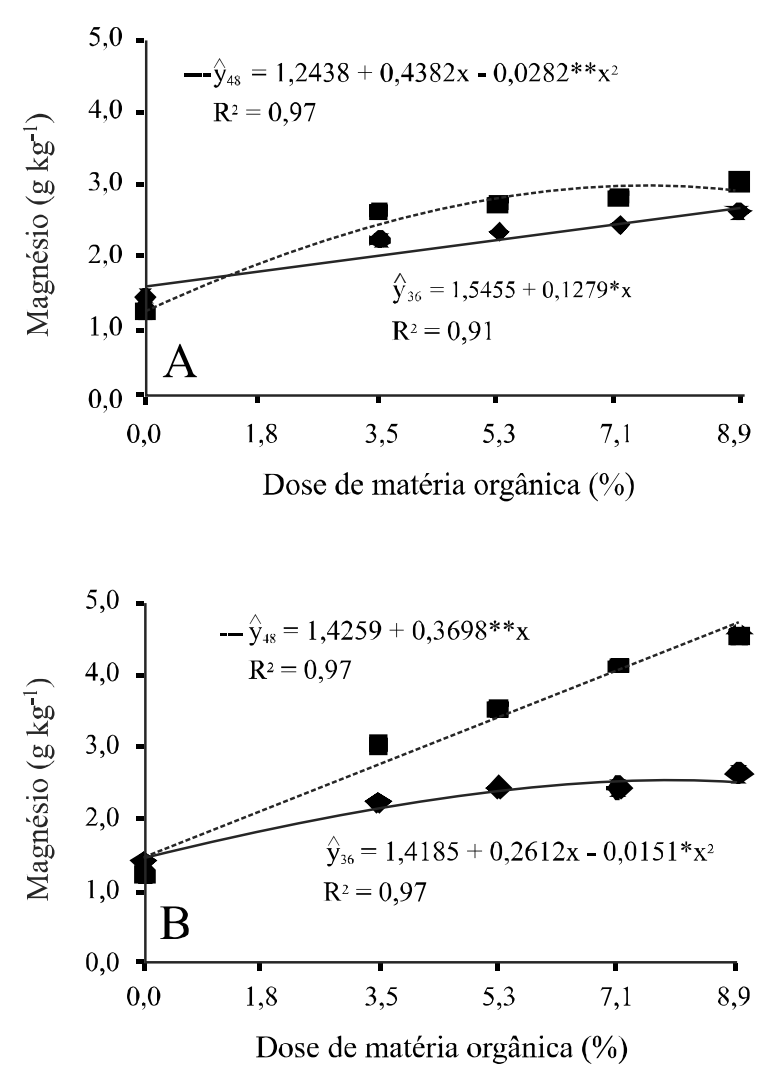

$\mathrm{O}$ aumento dos teores foliares em função das doses se deve ao fato das maiores doses de matéria orgânica aportar também maiores quantidades de magnésio ao solo. No entanto, os resultados obtidos são inferiores aos verificados por Santos et al. (2001) e Nascimento et al. (2002). Partindo das informações de Silva e Silva (1984) para absorção de quantidades adequadas de nutrientes pelas anonáceas, as plantas não foram supridas adequadamente em magnésio pelas fontes e doses de matéria orgânica.

Verifica-se ainda que os teores de magnésio nas plantas com 48 meses foram maiores que os das plantas com 36, independentemente da fonte de matéria orgânica utilizada (Figura 5), o que pode ser resposta a teores mais elevados no solo quando as plantas estavam com 48 meses, já que as aplicações de matéria orgânica eram realizadas a cada 120 dias e também ao fato das plantas possivelmente estarem iniciando sua fase produtiva, o que aumenta a necessidade e absorção de nutrientes. Com relação aos estercos aplicados percebe-se que aos 36 
meses estes exerceram ação semelhante na composição nutricional das plantas, mas quando estas estavam com 48 meses apresentaram maiores teores de magnésio em função da cama de frango, embora o teor deste elemento seja menor no respectivo insumo em relação ao esterco bovino (Tabela 1). Essa situação pode ser reflexo dos maiores teores de $\mathrm{K}$ do esterco bovino somados ao alto teor de potássio do solo que podem ter reduzido a absorção de magnésio oriundo do esterco bovino, em função de competição pelos sítios de absorção na membrana plasmática (MARSCHNER, 1997).

Independentemente da fonte aplicada, o incremento das doses de matéria orgânica elevaram os teores de enxofre do tecido foliar das plantas, mas com superioridade nas plantas com 48 meses de idade (Figura 6). Aos 36 meses, foi obtido o valor máximo $4,13 \mathrm{~g} \mathrm{~kg}^{-1}$ de enxofre correspondente à dose 7,36\% de matéria orgânica e aos 48 meses $10,94 \mathrm{~g} \mathrm{~kg}^{-1}$ referente à dose $6,17 \%$ de matéria orgânica. Esses resultados superam os obtidos por Nascimento et al. (2002).

Figura 6 - Teores de enxofre em matéria seca foliar de pinheira em função de doses de matéria orgânica aos 36 (-) e 48 (---) meses após plantio, em Remígio, 2010

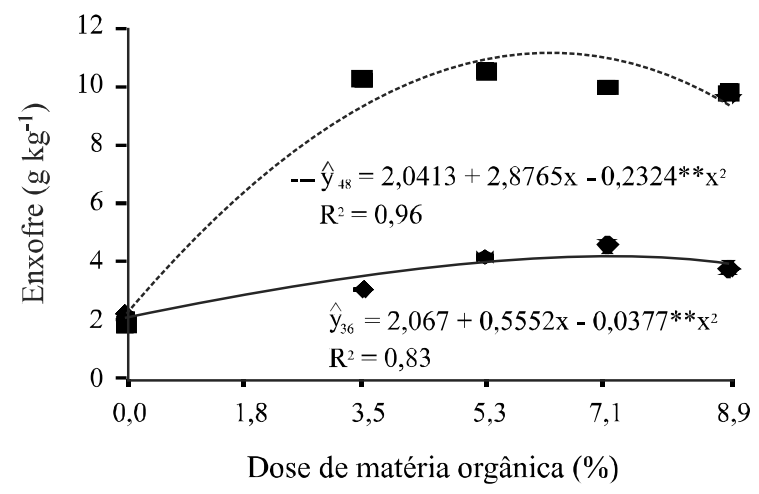

De acordo com Silva e Silva (1997) os teores de enxofre verificados em ambas as épocas de avaliação estão adequados para cultura da pinheira, possivelmente devido à matéria orgânica ser a principal fonte de enxofre para as plantas (LEONEL; DAMATTO JUNIOR, 2008). Aos 48 meses de idade as plantas apresentaram teores de enxofre expressivamente mais elevados do que aos 36 meses, possivelmente em respostas às aplicações de matéria orgânica a cada 120 dias e possível início da fase produtiva, onde as plantas requerem uma quantidade maior de nutrientes.
Os teores de boro, da matéria seca foliar, foram influenciados pela ação isolada das doses de matéria orgânica e épocas de avaliação nutricional da pinheira (Figura 7). Observa-se que o incremento das doses de matéria orgânica elevou os teores de boro ao valor máximo $40,77 \mathrm{mg} \mathrm{kg}^{-1}$, correspondente à dose $6,55 \%$ de matéria orgânica (Figura 7A). Este resultado está muito abaixo dos $105 \mathrm{mg} \mathrm{kg}^{-1}$ de boro obtidos por Silva et al. (1984) em pinheiras comerciais. Considerando as informações de Silva e Silva (1997) para nutrição de gravioleira e pinheira estes teores são considerados insuficientes. Talvez os baixos teores de boro tenham sido provocados pela competição pelos mesmos sítios ativos entre B e N na membrana plasmática (MARSCHNER, 1997).

Figura 7 - Teores de boro em matéria seca foliar de pinheira em função de doses de matéria orgânica (A) aos 36 e 48 meses após plantio (B), em Remígio, 2010
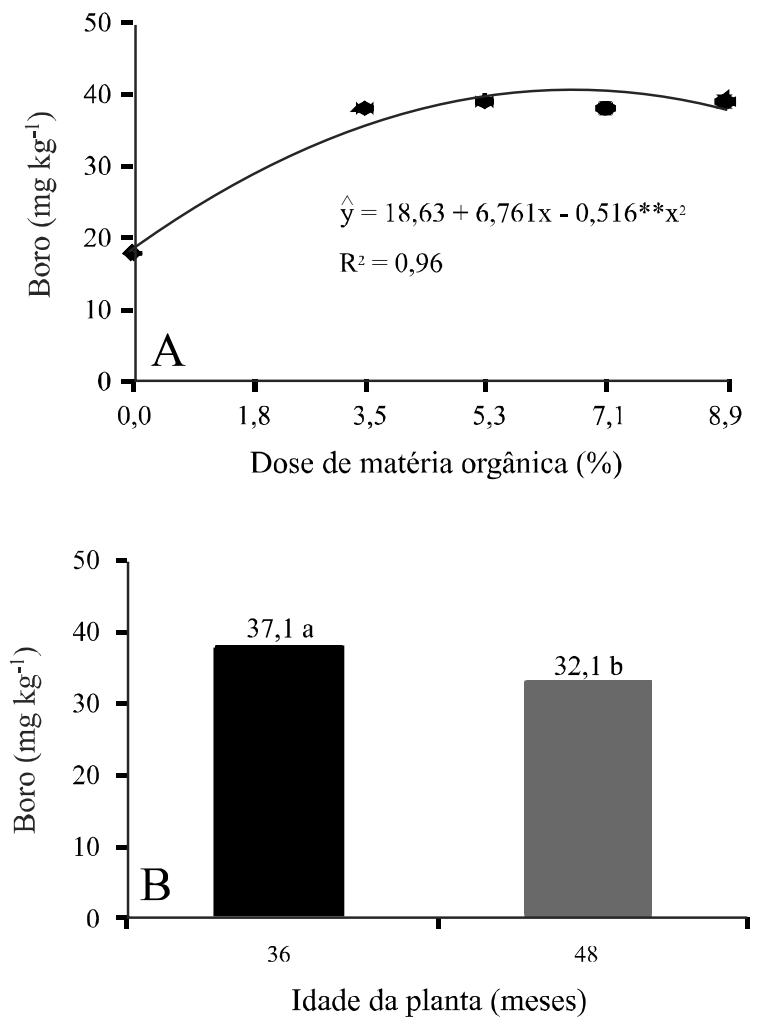

Com relação ao incremento nos teores de boro em função das doses de matéria orgânica, este pode estar relacionado a teores mais altos deste elemento nas maiores doses. Assim como ocorreu com os teores de $\mathrm{N}$, P e K, os teores de boro nas plantas com 36 meses 
superam os obtidos nas plantas aos 48 meses (Figura 7B), possivelmente em função das plantas estarem em início de fase produtiva demandando maiores teores de boro para formação de flores e frutos.

Independentemente da fonte, os teores de cobre da matéria seca foliar foram elevados em função do aumento das doses de matéria orgânica, com ajuste ao modelo quadrático em ambas as épocas de avaliação. Nas plantas com 36 meses de idade obteve-se o valor máximo $6,13 \mathrm{mg} \mathrm{kg}^{-1}$ de cobre, correspondente à dose $6,13 \%$ de matéria orgânica e naquelas com 48 meses $9,19 \mathrm{mg} \mathrm{kg}^{-1}$, correspondente a dose 6,4\% (Figura 8).

Figura 8 - Teores de cobre em matéria seca foliar de pinheira em função de doses de matéria orgânica aos 36 (-) e 48 (---) meses após plantio, em Remígio, 2010

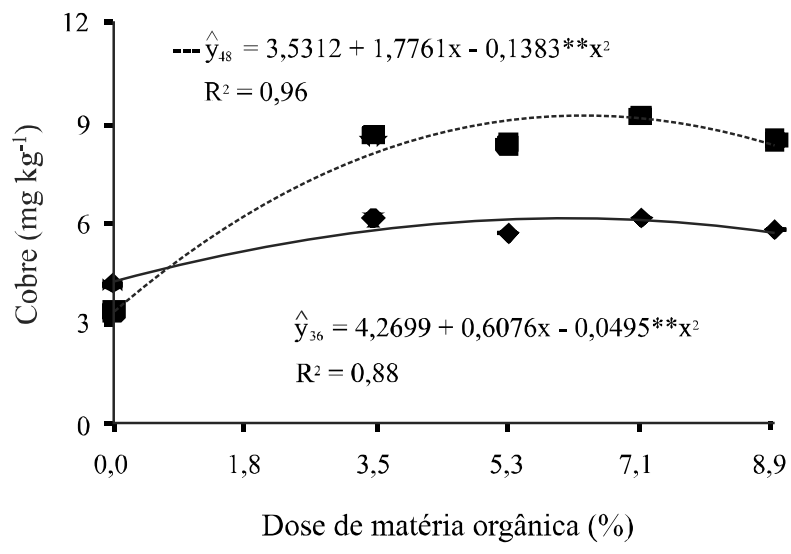

Verificou-se ainda que os teores de cobre nas plantas com 48 meses foram superiores aos das plantas com 36 meses de idade, talvez em função da maior quantidade de nutriente requerida pelas plantas para iniciarem a fase produtiva. A literatura pertinente não cita teores adequados de cobre para a cultura pinha, mas partindo da idéia de que Malavolta, Vitti e Oliveira (1997) e Dechen e Nachtigall (2006) consideram que a grande maioria das plantas cultivadas de importância comercial estão adequadamente nutridas com teores foliares de cobre entre 5 e $20 \mathrm{mg} \mathrm{kg}^{-1}$, os resultados obtidos são considerados adequados para cultura da pinha.

Independentemente da fonte de matéria orgânica aplicada, o incremento das doses elevaram os teores de ferro da matéria seca foliar da pinheira, mas aos 48 meses de idade as plantas apresentaram teores superiores aos verificados aos 36 meses (Figura 9).
Embora não tenham sido realizadas análises para verificar as quantidades de micronutrientes dos insumos orgânicos, possivelmente este aumento do teor de ferro nas plantas em função das doses de matéria orgânica ocorre devido às maiores doses conterem maiores teores de ferro.

Figura 9 - Teores de ferro em matéria seca foliar de pinheira em função de doses de matéria orgânica aos 36 (-) e 48 (---) meses após plantio, em Remígio, 2010

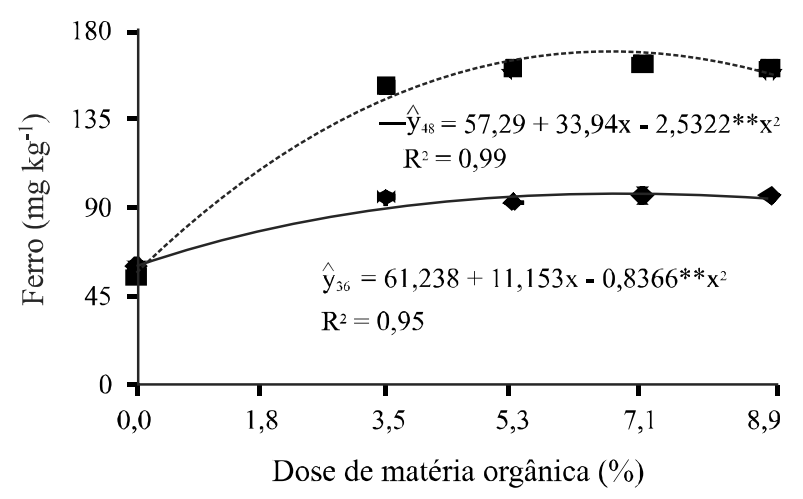

Verificou-se nas plantas com 36 meses, $98,34 \mathrm{mg} \mathrm{kg}^{-1}$, de ferro correspondente à dose $6,66 \%$ de matéria orgânica e nas plantas com 48 meses $171 \mathrm{mg} \mathrm{kg}^{-1}$ correspondente à dose $6,70 \%$. Os teores de ferro obtidos nas plantas com 36 meses são inferiores, mas os obtidos aos 48 meses são superiores aos verificados por Silva et al. (1984) em pinheiras adultas. Assim como para o cobre, não são encontradas na literatura informações à respeito dos teores adequados de ferro para pinheira, mas os valores máximos obtidos nas duas épocas de avaliação estão próximos ou acima dos teores adequados registrados por Malavolta, Vitti e Oliveira (1997) para maioria das frutíferas analisadas. Para Dechen e Nachtigall (2006), teores de ferro entre 50 e $100 \mathrm{mg} \mathrm{kg}^{-1}$ são considerados como adequados para a maioria das plantas comercias.

A interação fonte de matéria orgânica $\mathrm{x}$ dose $\mathrm{x}$ época de avaliação influenciou o acúmulo de zinco na matéria seca foliar da pinheira (Figura 10). Observa-se que independentemente das fontes de matéria orgânica e épocas de avaliação, o aumento das doses de matéria orgânica elevou os teores de zinco da matéria seca foliar das plantas, o que pode ser resposta a possíveis teores mais elevados deste nutriente em função da aplicação de maiores volumes de esterco. 
Figura 10 - Teores de zinco em tecido foliar de pinheira em função de doses de matéria orgânica, proviniente de esterco bovino (A) e cama de frango (B) aos 36 (-) e 48 meses (---) após plantio, em Remígio, 2010

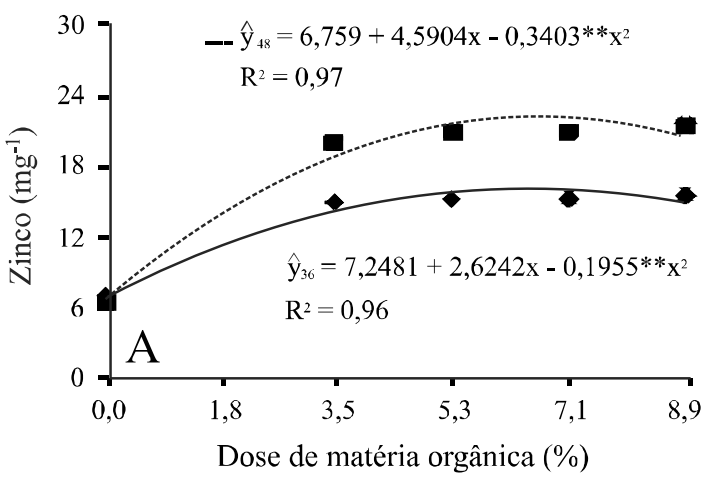

Nos tratamentos com esterco bovino os teores máximos verificados nas plantas aos 36 e 48 meses de idade foram 16,05 e $22,24 \mathrm{mg} \mathrm{kg}^{-1}$, correspondentes às doses 6,71 e 6,74\% de matéria orgânica, respectivamente (Figura 10A). Por outro lado, nas plantas tratadas com cama de frango os teores máximos de zinco verificados aos $36 \mathrm{e}$ 48 meses foram 16,63 e $15,11 \mathrm{mg} \mathrm{kg}^{-1}$, correspondentes às doses 6,72 e 7,04\% de matéria orgânica, respectivamente (Figura 10B). Observa-se que nos tratamentos com esterco bovino (Figura 10A), as plantas com 48 meses de idade apresentaram teores de zinco superiores aos das plantas com 36 meses, mas nos tratamentos com cama de frango o comportamento foi inverso. Verificou-se ainda que nas plantas com 36 meses os teores de zinco foram praticamente semelhantes, quando adubadas com esterco bovino ou cama de frango, mas aos 48 meses, as plantas apresentam maiores teores de zinco quando adubadas com esterco bovino (Figura 10A), possivelmente devido a inibição na absorção desse elemento provocada pelos teores de cálcio mais elevados na cama de frango. Segundo Malavolta, Vitti e Oliveira (1997) teores altos de cálcio no solo diminuem a absorção de zinco pelas plantas, além disso a fonte de fósforo também apresenta cálcio em sua composição o que pode ter acentuado o processo. Os teores obtidos, independentemente da fonte utilizada, em ambas as épocas de avaliação estão abaixo de $25 \mathrm{mg} \mathrm{kg}^{-1}$, valor considerado por Dechen e Nachtigall (2006) como valor crítico para a grande maioria das cultura comerciais, além disso, para maioria das frutíferas Malavolta, Vitti e Oliveira, (1997) consideram teores de zinco acima de $20 \mathrm{mg} \mathrm{kg}^{-1}$ como adequados.

Com relaçãoà deficiência em alguns micronutrientes apresentada pelas plantas, umaexplicaçãoseriaumapossível elevação do teor de matéria orgânica do solo em função das aplicações de esterco a cada 120 dias, pois Dechen e Nachtigall (2006) reportam que vários autores relatam

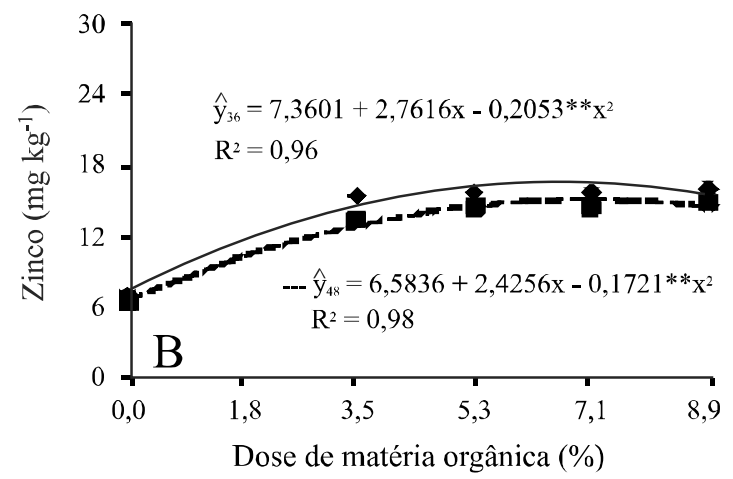

aumento do teor de micronutrientes no solo em função do aumento de matéria orgânica no solo; contudo em algumas situações a formação de complexos organometálicos diminui a disponibilidade de micronutrientes, em função do decréscimo da atividade deles na solução do solo, mas posteriormente com decomposição do material orgânico complexante eles voltam a ficar disponíveis, e por isso afirmam que os solos com elevados teores de matéria orgânica são os que, com mais freqüência mostram deficiências de um ou mais nutrientes, o que se agrava em solos naturalmente pobres nestes.

\section{CONCLUSÕES}

1. Em ambas as épocas avaliadas, as fontes de matéria orgânica proporcionaram teores adequados de nitrogênio, potássio, enxofre, cobre, ferro e zinco às plantas, mas não de fósforo, cálcio, magnésio, boro e manganês;

2. Com exceção de magnésio e zinco, as fontes de matéria orgânica não exercem diferenças entre si sobre os teores dos demais nutrientes na matéria seca foliar de pinheira;

3. A dose de máxima eficiência verificada para o acúmulo de nutrientes no tecido foliar de pinheira está entre 6,0 e $8,65 \%$ de matéria orgânica.

\section{REFERÊNCIAS}

AZEEZ, J. O.; AVERBEKE, W. V.; OKOROGBONA, A. O. M. Differential responses in yield of pumpkin (Cucurbita maxima L.) and nightshade (Solanum retroflexum Dun.) to the application of three animal manures. Bioresource Technology, v. 101, n. 7, p. 2499-2505, 2010. 
BHATTI , T. M.; YAWAR, W. Bacterial solubilization of phosphorus from phosphate rock containing sulfur-mud. Hydrometallurgy, Amsterdam v. 103, n. 1, p. 54-59, 2010.

DECHEN, A. R.; NACHTIGAL, G. R. Micronutrientes In: FERNANDES, M. S. Nutrição mineral de plantas. Viçosa: Sociedade Brasileira de Ciência do Solo, 2006. cap. 13, p. 327-354.

FARIDULLAH, M. I. et al. Characterization of trace elements in chicken and duck litter ash. Waste Management, v. 29, n. 1, p. 265-271, 2009.

LEONEL, S.; DAMATTO JUNIOR, E. R. Efeitos do esterco de curral na fertilidade do solo, no estado nutricional e na produção da figueira. Revista Brasileira de Fruticultura, v. 30, n. 2, p. 534-539, 2008.

LAZCANO, C.; GÓMEZ-BRANDÓN, M.; DOMÍNGUEZ, J. Comparison of the effectiveness of composting and vermicomposting for the biological stabilization of cattle manure. Chemosphere, v. 72, n. 04, p. 1013-1019, 2008.

MALAVOLTA, E.; VITTI, G. C.; OLIVEIRA, S. A. Avaliação do estado nutricional das plantas: princípios e aplicações. Piracicaba: POTAFOS, 1997. 201 p.

MARSCHNER, H. Mineral nutrition of higher plants. 6. ed. Londres: Academic Press, 1997. 889 p.

MENEZES, R. S. C.; SALCEDO. I. H. Mineralização de $\mathrm{N}$ após incorporação de adubos orgânicos em um Neossolo Regolítico cultivado com milho. Revista Brasileira de Engenharia Agrícola e Ambiental, v. 11, n. 4 p. 361-367, 2007.

NASCIMENTO, V. M. et al. Avaliação do estado nutricional de 10 pomares de pinha na Região de Jales. In: CONGRESSO BRASILEIRO DE FRUTICULTURA, 17., 2002, Belém. Anais... Belém: SBF, 2002. 1 CD-ROM.
NIETSCHE, S. et al. Viabilidade dos grãos de pólen de flores de pinheira (Annona squamosa L.) em diferentes horários. Ciência e Agrotecnologia, v. 33, n. 2, p. 527-531, 2009.

SADHU, M. K.; GHOSH, S. K. Effects of different level of nitrogen, phosphorus and potassium on growth, flowering, fruiting and tissue composition of custard (Annona squamosa L.). Indian Agricultural, v. 20, n. 4, p. 297-301, 1976.

SANTOS, E. D. P. et al. Comportamento vegetativo e produtivo da pinheira sob níveis de água e tipos de cobertura morta do solo. Anais do curso de Pós-Graduação e Manejo de Solo e Água, Areia, v. 23, p. 74-95, 2001

SANTOS, H. G. et al. Sistema brasileiro de classificação de solos. 2. ed. Rio de Janeiro: Embrapa Solos, 2006. 306 p.

SÃO JOSÉ, A. R. Cultivo e Mercado da Graviola. Fortaleza: Instituto Frutal, 2003. 36 p.

SILVA, A. Q.; SILVA, H. Nutrição e adubação de anonáceas. In: SÃO JOSÉ, A. B. ( Ed.). Anonáceas: produção e mercado (pinha, graviola, atemóia e cherimólia). Vitória da Conquista: DFZ/UESB, 1997. cap. 17, p. 118-137.

SILVA, H. et al. Composição mineral das folhas de algumas frutíferas do Nordeste. In: CONGRESSO BRASILEIRO DE FRUTICULTURA, 7., Florianópolis 1983. Anais... Florianópolis: SBF/EMPASC, 1984, p. 320-325. v. 1.

SOUZA, R. F. et al. Influência de esterco bovino e calcário sobre o efeito residual da adubação fosfatada para a brachiaria brizantha cultivada após o feijoeiro. Revista Brasileira de Ciência do Solo, v. 34, n. 1, p. 143-150, 2010.

VIDIGAL S. M. et al. Produtividade de cebola em cultivo orgânico utilizando composto à base de dejetos de suínos. Horticultura Brasileira, v. 28, n. 2, p. 168-173, 2010.

ZUCARELI, V. et al. Luz e Temperatura na Germinação de Sementes de Annona squamosa L. Revista Brasileira de Biociências, v. 5, p. 840-842, 2007. Suplemento 2. 